\title{
Bcl-2 overexpression sensitizes MCF-7 cells to genistein by multiple mechanisms
}

\author{
CHAITALI TOPHKHANE ${ }^{1}$, SHIHE YANG ${ }^{1}$, WESLEY BALES $^{2}$, LINDA ARCHER ${ }^{1,2}$, \\ ADEBOYE OSUNKOYA $^{1}$, ANN D. THOR ${ }^{3}$ and XIAOHE YANG ${ }^{1}$ \\ ${ }^{1}$ Department of Pathology, University of Oklahoma Health Sciences Center; ${ }^{2}$ Veterans Affairs \\ Medical Center of Oklahoma, Oklahoma City, OK 73104; ${ }^{3}$ Department of Pathology, \\ University of Colorado Health Sciences Center, Aurora, CO 80045, USA
}

Received April 17, 2007; Accepted June 11, 2007

\begin{abstract}
Genistein is a soy isoflavone with anti-tumor properties. Genistein-induced apoptosis involves Bcl-2 downregulation. However, overexpression of $\mathrm{Bcl}-2$ in breast cancer has been associated with better prognosis and response to hormonal therapy. To examine genistein's effect on breast cancer cells with different Bcl-2 levels, we established control (MCF-7/PV) and Bcl-2 overexpressing MCF-7 (MCF-7/Bcl-2) cell lines and characterized genistein regulated apoptosis and cell cycle progression in these cells. Our results demonstrate that overexpression of Bcl-2 rendered MCF-7 cells more sensitive, rather than resistant, to genistein. We found that genistein induces enhanced cytochrome $c$ release and mitochondrial membrane depolarization in $\mathrm{MCF}-7 / \mathrm{Bcl}-2$ cells, as compared to control. We also found that genistein increases $\mathrm{Bcl}-2$ levels and $\mathrm{Bcl}-2 / \mathrm{Bax}$ ratio in the mitochondrial fractions of $\mathrm{MCF}-7 / \mathrm{Bcl}-2$ cells, suggesting that disturbed $\mathrm{Bcl}-2 / \mathrm{Bax}$ distribution may cause cytochrome $c$ release and apoptosis in these cells. Cell cycle analysis indicated that genistein induces $\mathrm{G} 0 / \mathrm{G} 1$ arrest in MCF-7/PV cells but increases in $\mathrm{G} 2 / \mathrm{M}$ arrest in $\mathrm{MCF}-7 / \mathrm{Bcl}-2$ cells. This was accompanied by modified responses of several cell cycle regulators, such as p21 and cyclin B1. Taken together, our results indicate that genistein-Bcl-2 interaction switches Bcl-2 from an antiapoptotic protein into a proapoptotic protein, which involves disturbed $\mathrm{Bcl}-2 / \mathrm{Bax}$ distribution in mitochondria, increased cytochrome $c$ release and modified cell cycle regulation.
\end{abstract}

\section{Introduction}

High intake of soy products has been associated with low incidence of breast cancers in Asian countries (1,2). Many soy-mediated anti-tumor properties have been attributed to

Correspondence to: Dr Xiaohe Yang, Department of Pathology, University of Oklahoma Health Sciences Center, Oklahoma City, OK 73104, USA

E-mail: xiaohe-yang@ouhsc.edu

Key words: genistein, Bcl-2, apoptosis, mitochondria, cell cycle genistein, a major soy isoflavone (3). Results from both in vitro and animal studies indicate that genistein may inhibit tumor cell growth by multiple mechanisms (3-5). As a typical phytoestrogen, genistein binds to estrogen receptors (ERs) and modulates hormonal signaling of breast epithelial and cancer cells (6-8). For ER positive breast cancer cells, genistein inhibits cancer cells at higher concentrations, but stimulates cell growth at lower concentrations $(9,10)$. Genistein is also known as a potent inhibitor of tyrosine kinases, such as EGFR (11-13), and a topoisomerase inhibitor (14). In addition, it was reported that genistein can activate the JNK pathway and inhibit NF- $\mathrm{KB}$ activity $(15,16)$. As a result, integrated signaling from these pathways induces cell cycle arrest and, in particular, apoptosis, both of which play important roles in genistein mediated anti-tumor activities $(3,17,18)$.

Genistein-induced apoptosis has been examined in a variety of cancer cell lines, including breast, prostate, pancreatic and lung cancers (3). Most reports indicate that genistein mediated apoptosis was accompanied by modulation of many p53 target genes, such as p21 and Bax, and the activation of the mitochondrial pathway $(18,19)$. However, genistein-induced apoptosis could be p53 independent, because many cell lines that have p53 mutation were sensitive to genistein $(7,18)$. On the basis of Bax upregulation and Bcl-2 downregulation in genistein treated cells, it was proposed that increase of Bax/Bcl-2 ratio is a key factor that initiates apoptotic cascade through the mitochondrial pathway $(18,20)$. Nevertheless, the involvement of Bcl-2 in genistein-induced apoptosis was merely based on the association between growth inhibition and the Bcl-2 downregulation. The role of Bcl-2 in genisteininduced apoptosis remains to be defined.

Bcl-2 is the founding member of the Bcl-2 family, which consists of both anti-apoptotic and pro-apoptotic proteins, such as pro-apoptotic Bax, Bak and Bid, and anti-apoptotic $\mathrm{Bcl}-2$, Bcl-xL and Bcl-W $(21,22)$. The proapoptotic proteins Bax and Bak induce cell death by modulating mitochondrial membrane permeability, which leads to the release of cytochrome $c$ and the activation of caspase cascade (23). By forming heterodimers with pro-apoptotic family members, Bcl-2 inhibits Bax/Bak activation and prevents the release of cytochrome $c$, resulting in cell survival (24). Overexpression of Bcl-2 is generally associated with tumor development, 
progression and drug resistance, especially in leukemia $(25,26)$. Although Bcl-2 overexpression is implicated in cell survival in most cases, increasing reports indicate that $\mathrm{Bcl}-2$ overexpression is associated with a better prognosis in many solid tumors $(27,28)$. In particular, Bcl-2 is overexpressed in about $40-70 \%$ of breast cancers. Overexpression of Bcl-2 in these tumors was associated with better overall outcomes and responses to hormonal therapy (29).

Previous studies have shown that genistein downregulates Bcl-2 in different cells (3). Little is known about the effect of genistein on cells with different Bcl-2 levels. Given that breast cancers with different Bcl-2 status have distinct prognostic significance and therapeutic responses (30), we questioned whether cells with different Bcl-2 levels respond to genistein differently. Based on control and Bcl-2 overexpressing MCF-7 cell line models, we found that genistein induces enhanced cell death and growth inhibition in MCF-7 cells overexpressing high levels of Bcl-2. Our results suggest that genistein interacts with Bcl-2 at multiple levels, and that breast cancers with high levels of Bcl-2 might benefit more from genistein treatment.

\section{Materials and methods}

Reagents. Genistein, 3-(4, 5-dimethylthiazol-2-yl)-2, 5diphenyltetrazolium bromide (MTT), DMEM/F12 medium and other chemicals were purchased from Sigma (St. Louis, MO). Antibodies against Bcl-2, p21, p27, cyclin D1, p53, Poly ADP-ribose polymerase (PARP) and Actin were purchased from Santa Cruz Biotechnology (Santa Cruz, CA). Antibody against cyclin B1 was from Rockland Immunochemicals (Gilbertsville, PA). Horseradish peroxidase (HRP)-labeled secondary antibodies were purchased from Amersham/GE Health Care (Arlington Height, IL). pCR-Bcl-2 plasmid was a generous gift from Dr John Reed (Burnham Institute, CA).

Cell culture and transfection. MCF-7 breast cancer cell line was purchased from American Type Culture Collection (ATCC). The cells were cultured in DMEM/F12 medium containing $10 \%$ fetal bovine serum (FBS). For drug treatment, $1.5 \times 10^{6}$ cells were inoculated into a $60 \mathrm{~mm}$ dish $24 \mathrm{~h}$ before treatment. The cells were then treated with genistein at indicated concentrations for various durations. The control cells were treated with $0.1 \%$ DMSO. For transfection, $3 \times 10^{5}$ cells were inoculated into a $35-\mathrm{mm}$ dish $24 \mathrm{~h}$ before transfection. Transfection was performed using FuGENE 6 (Roche, IN) according to the manufacturer's protocol. Bcl-2 overexpressing MCF-7/Bcl-2 cell line was established by transfecting MCF-7 cells with pCR-Bcl-2 plasmid encoding human Bcl-2 cDNA, followed by G418 selection. G418 resistant clones were pooled for further characterization. The control cells were MCF-7 cells transfected on an empty pBabe/puro vector (MCF-7/pv) (31). $\mathrm{MCF}-7 / \mathrm{C} 3 / \mathrm{Bcl}-2$ cell line was established by transfection of MCF-7/C3 (31) cells with pCR-Bcl-2 followed by G418 selection.

MTT assay. For MTT assay, the cells were inoculated into 96-well plates at $1 \times 10^{3}$ cells/well $24 \mathrm{~h}$ before the treatment. The cells were treated with increasing concentrations of genistein $(0.023-50 \mu \mathrm{M})$ for 6 days. After removal of the medium, $50 \mu 1$ of MTT solution $(500 \mu \mathrm{g} / \mathrm{ml})$ was added to each well followed by $4-\mathrm{h}$ incubation. MTT solution was replaced by DMSO to dissolve blue formazan crystals, and absorbance was measured at $562 \mathrm{~nm}$ using a microplate reader. Survival fractions were calculated based on MTT incorporation in the treated cells over the control groups of each cell line. Eight parallel samples were tested. Statistical difference was analyzed using Student's t-test.

Clonogenic assay. Six hundred cells were seeded into 60-mm dishes for $24 \mathrm{~h}$ before treatment. The cells were then treated with different doses of genistein $(0,2.5,5,10$ and $20 \mu \mathrm{M})$ for 12 days in culture. Cell colonies were stained with $0.5 \%$ crystal violet in $25 \%$ methanol for 10 min followed by three rinses with water. The number of survival colonies was counted, and pictures were taken using UPV II imaging system. The experiments were performed in triplicate. Statistical difference was analyzed using Student's t-test.

Western blotting. The cells were lysed with lysis buffer containing $50 \mathrm{mM}$ Tris, $5 \mathrm{mM}$ EDTA, $150 \mathrm{mM} \mathrm{NaCl}, 0.5 \%$ NP-40 and protease inhibitors. Protein concentration was determined using BCA assay kit (Pierce Biotechnology Inc. IL). Fifty $\mu \mathrm{g}$ of protein lysate was loaded onto each lane of a gel. Proteins were separated with $12 \%$ or $15 \%$ SDS-PAGE and transferred to nitrocellulose membrane. The membrane was probed with a specific primary antibody at a dilution of 1:300 to 2000 , followed by washing and probing with a corresponding secondary antibody. The specific protein band was visualized by autoradiography using an ECL kit (GE Health Care).

Cytochrome c release assay. The cytosolic extract for cytochrome $c$ release experiments was prepared according to previously published protocol (32). In brief, treated cells were washed with PBS and resuspended in sucrose containing buffer. After 30-min incubation, the cells were disrupted by 30 strokes with a glass Dounce (Type B). The large debris in the cell homogenates was cleaned by centrifugation at $880 \mathrm{~g}$ for $10 \mathrm{~min}$. Mitochondria in the supernatant were separated by further centrifugation at $22,000 \mathrm{~g}$ for $15 \mathrm{~min}$. The resulting supernatants were saved as cytosolic extract. Cytochrome $c$ in this extract was detected using Western blotting described above.

Flow cytometry for cell cycle analysis. MCF-7/PV and MCF-7/ $\mathrm{Bcl}-2$ cells were treated with different concentrations of genistein for $48 \mathrm{~h}$. The cells were then fixed with $80 \%$ ethanol. After being washed three times with PBS containing $0.1 \%$ Triton X-100 and treated with RNase A (1 mg/ml) for $30 \mathrm{~min}$, the cells were stained with $50 \mu \mathrm{g} / \mathrm{ml}$ propidium iodide. Cell analysis was performed using a FACSCalibur flow cytometer (Becton-Dickinson). The fraction of the total cell population present in the G1, S phase, G2-M phase was obtained from DNA histograms by mathematical modeling using MultiFit software.

Analysis of mitochondrial depolarization. Mitochondrial depolarization was examined by JC-1 staining and flow cytometry. This assay is based on the principle that fluorescence of JC-1 changes with mitochondrial membrane potential. Red 


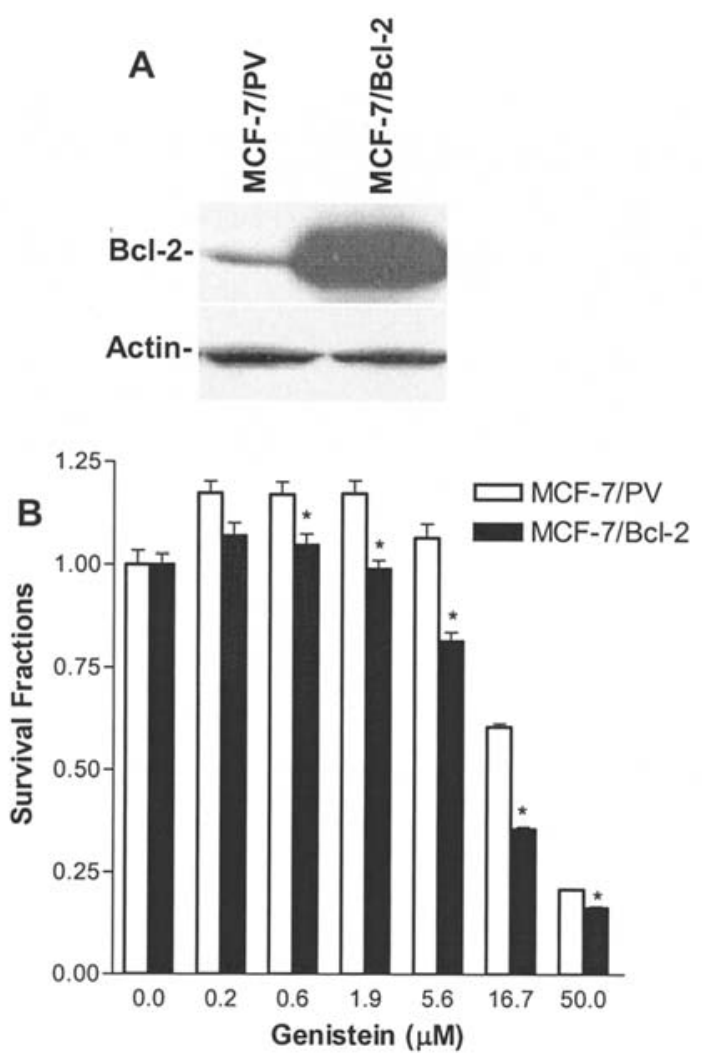

Figure 1. Bcl-2 overexpression in MCF-7 cells sensitizes the cells to genistein. A, Establishment of control and Bcl-2 overexpressing MCF-7 cells. MCF-7 cells were transfected with $\mathrm{pCR} / \mathrm{Bcl}-2$ or control vector (PV) followed by G418 selection. G418 resistant clones were pooled for further studies. Bcl-2 levels in MCF-7/PV and MCF-7/Bcl-2 cells were detected by Western blotting. $\mathrm{B}$, Effects of genistein on $\mathrm{MCF}-7 / \mathrm{PV}$ and $\mathrm{MCF}-7 / \mathrm{Bcl}-2$ cell proliferation. $\mathrm{MCF}-7 / \mathrm{PV}$ and $\mathrm{MCF}-7 / \mathrm{Bcl}-2$ cells were treated with genistein at indicated concentrations for 6 days, followed by MTT assay. Survival fractions of the treated cells, based on 8 parallel samples, were statistically analyzed. ${ }^{*} \mathrm{P}<0.01$.

fluorescence indicates intact mitochondria. As mitochondrial depolarization occurs the cells gain green fluorescence and lose red fluorescence in particular. In these experiments, genistein treated cells were trypsinized, followed by washing with PBS. The cells were then stained with $1 \mu \mathrm{M} \mathrm{JC}-1$ (Molecular Probes, Eugene, OR) in serum free DMEM/F12 medium at $37^{\circ} \mathrm{C}$ for $20 \mathrm{~min}$, followed by washing with color free DMEM/F12. For flow cytometry analysis, detectors FL-1 and FL-2 were set to measure green and red fluorescence respectively. The percentage of cells in each quadrant was calculated using the WinMDI 2.8 software. Cells in the lower right quadrant represent the cells with mitochondrial depolarization.

\section{Results}

Bcl-2 overexpression sensitizes MCF-7 cells to genistein. In order to determine the effect of Bcl-2 overexpression on genistein-induced growth inhibition, we first established control (MCF-7/PV) and Bcl-2 overexpressing MCF-7 (MCF-7/Bcl-2) cell lines as detailed in Materials and methods. As shown in Fig. 1A, MCF-7/Bcl-2 cells express significantly higher levels of Bcl-2 than the control cells. We then examined the responsiveness of the two isogenic cell lines to genistein using MTT assay. To our surprise, cells overexpressing
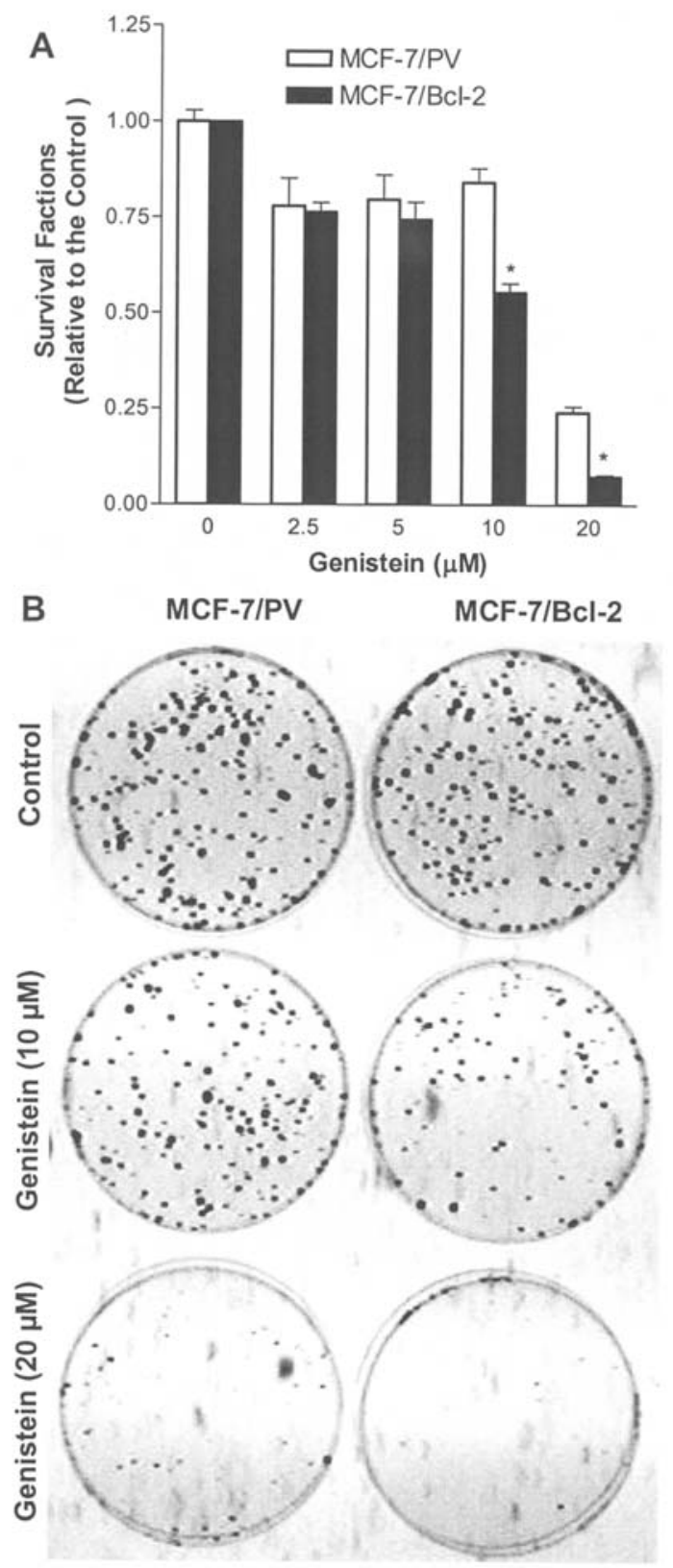

Figure 2. Enhanced growth inhibition in genistein treated MCF-7/Bcl-2 cells determined by clonogenic assay. MCF-7/PV and MCF-7/Bcl-2 cells at 600 cells/60-mm dish were treated with genistein (control/DMSO, 10 or $20 \mu \mathrm{M}$ ) for 12 days, followed by crystal violet staining. The number of survival colonies on each dish was counted, and the pictures were taken using UPV II Imaging system. The experiments were performed in triplicate. ${ }^{*} \mathrm{p}<0.01$.

anti-apoptotic Bcl-2 were more sensitive to genistein than the control cells in a dose-dependent manner (Fig. 1B). Genistein treated MCF-7/PV cells displayed a bi-phasic response, i.e., enhanced proliferation at lower doses $(<5.6 \mu \mathrm{M})$ but inhibited growth at higher concentration, which is consistent with previous reports (33). In contrast, the survival fractions of genistein treated $\mathrm{MCF}-7 / \mathrm{Bcl}-2$ cells were consistently lower as compared to that of MCF-7/PV cells under the same conditions.

To confirm that Bcl-2 overexpressing cells are more sensitive to genistein, we performed clonogenic assays, in which control and MCF-7/Bcl-2 cells were treated with 0 , $2.5,5,10$ and $20 \mu \mathrm{M}$ of genistein for 12 days. As shown in Fig. 2, the survival fractions of all genistein treated MCF-7/ 


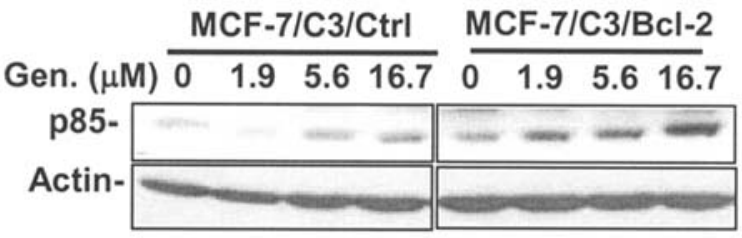

Figure 3. PARP cleavage in caspase-3 reconstituted MCF-7 cells (MCF-7/C3) with/without Bcl-2 overexpression. MCF-7/C3 control (MCF-7/C3/Ctrl) and MCF-7/C3/Bcl-2 cells were treated with genistein (Gen.) at indicated concentrations for $48 \mathrm{~h}$. Production of p85, a major subunit of cleaved PARP, was detected using Western blotting.

Bcl-2 groups were lower than MCF-7/pv cells. The most significant differences between the two cells lines were observed in 10 and $20 \mu \mathrm{M}$ groups. These results demonstrate that MCF-7 cells overexpressing Bcl-2 were indeed more sensitive to genistein than low $\mathrm{Bcl}-2$ expressing cells.

PARP cleavage in genistein treated MCF-7C3//Bcl-2 cells. Caspase-mediated cleavage of PARP is a common marker of apoptosis. We tried to use PARP cleavage to indicate the enhanced apoptosis in genistein treated $\mathrm{MCF}-7 / \mathrm{Bcl}-2$ cells. However, due to caspase-3 deficiency in MCF-7 cells (31), PARP cleavage was not sensitive in these cells (data not shown). We then established MCF-7/C3/Bcl-2 cell line [MCF-7/C3 cells are MCF-7 cells reconstituted with caspase-3 (31)] and examined PARP cleavage in genistein treated $\mathrm{MCF}-7 / \mathrm{C} 3 / \mathrm{control}$ and $\mathrm{MCF}-7 / \mathrm{C} 3 / \mathrm{Bcl}-2$ cells. As shown in Fig. 3, genistein treatment results in increased levels of $\mathrm{p} 85$, a major subunit of cleaved PARP, in MCF-7/C3/Bcl-2 cells as compared to $\mathrm{MCF}-7 / \mathrm{C} 3 / \mathrm{control}$ cells. This result suggests that enhanced activation of caspase cascade is involved in Bcl-2 overexpression mediated sensitization of $\mathrm{MCF}-7$ cells to genistein.

Genistein induces enhanced cytochrome c release and mitochondrial membrane depolarization in Bcl-2 overexpressing $M C F-7$ cells. Since the immediate functional target of Bcl-2 is mitochondrial membrane permeability, we examined the effect of genistein on cytochrome $c$ release from the mitochondria of control and MCF-7/Bcl-2 cells. Cytosolic fraction was extracted from each of the cell lines treated with DMSO, $50 \mu \mathrm{M}$ of genistein or $1 \mu \mathrm{M}$ of doxorubicin (serving as a control of DNA damaging agent) for $48 \mathrm{~h}$. Under the given conditions, cytochrome $c$ in the cytosolic fraction of DMSO treated MCF-7/PV cells was not detectable (Fig. 4). A weak band of cytochrome $c$, however, was detected in DMSO treated $\mathrm{MCF}-7 / \mathrm{Bcl}-2$ cells. After doxorubicin or genistein treatment, cytochrome $c$ levels in the cytosolic fractions of each cell line were increased as compared to their corresponding control. More importantly, the increase in genistein treated MCF-7/Bcl-2 cells was the most significant. These results suggest that cytochrome $c$ release was more susceptible in MCF-7/Bcl-2 cells, which may lead to enhanced apoptosis in these cells.

To further characterize the effect of genistein on mitochondrial membrane permeability, we examined mitochondrial membrane depolarization using JC-1 staining. In cells with intact mitochondria, JC-1 accumulates as aggregates in the

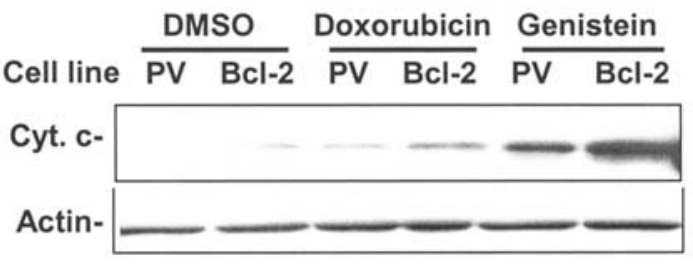

Figure 4. Enhanced cytochrome $c$ release from the mitochondria of genistein treated MCF-7/Bcl-2 cells. MCF-7/PV (PV) and MCF-7/Bcl-2 (Bcl-2) cells were treated with $0.1 \%$ DMSO, $1 \mu \mathrm{M}$ doxorubicin or $50 \mu \mathrm{M}$ of genistein for $48 \mathrm{~h}$. Cytosolic fractions were extracted from the treated cells using dunce homogenizer. Cytochrome $c$ (Cyt. $c$ ) in the cytosolic fractions was detected using Western blotting.
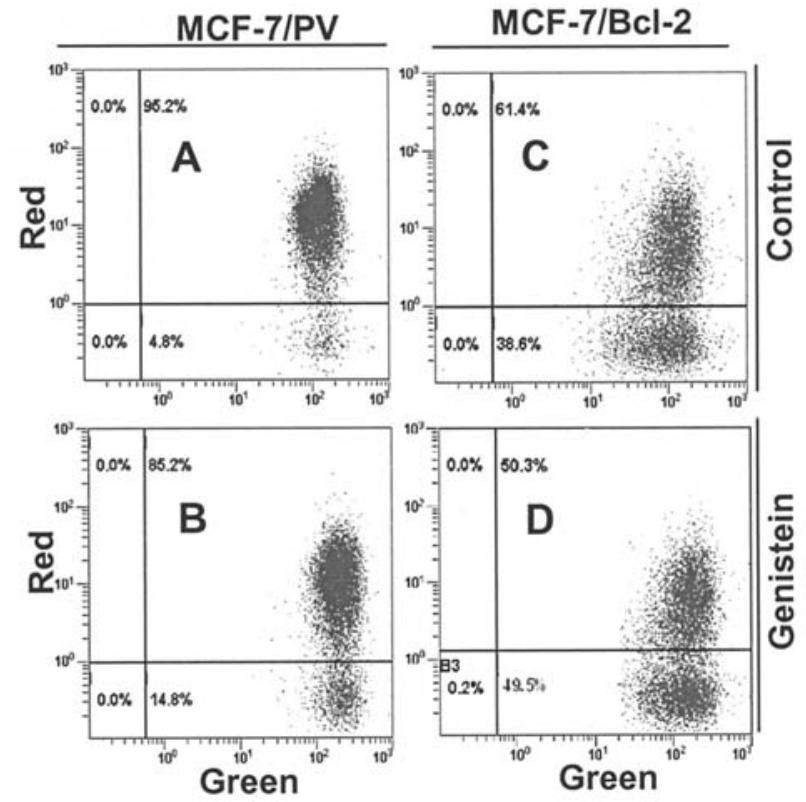

Figure 5. Mitochondrial depolarization in control and genistein treated $\mathrm{MCF}-7 / \mathrm{PV}$ and MCF-7/Bcl-2 cells. Cells of each line were treated with $0.1 \%$ DMSO or $25 \mu \mathrm{M}$ of genistein for $24 \mathrm{~h}$. The cells were then trypsinized and stained with $1 \mu \mathrm{M}$ of $\mathrm{JC}-1$ for $20 \mathrm{~min}$. The red and green fluorescence of the cells stained with JC-1 was analyzed using flow cytometry as described in Materials and methods. Cells in the lower-right quadrant are the cells with mitochondrial depolarization.

mitochondria, resulting in red fluorescence. Depolarization of mitochondria in JC-1 stained cells results in a decrease in red fluorescence and an increase in its green fluorescence (34). Based on flow cytometry analysis (Fig. 5), we found that genistein only induced a moderate mitochondrial depolarization (the cells in the lower-right quadrant) in MCF-7/PV cells (Fig. 5B). In contrast, MCF-7/Bcl-2 cells displayed a higher background in mitochondrial depolarization (Fig. 5C). In particular, the percentage of genistein treated MCF-7/Bcl-2 cells with mitochondrial depolarization was much higher than MCF-7/PV cells under the same conditions. These data, while showing that Bcl-2 overexpression alone may cause some spontaneous depolarization, further support the above finding that genistein induces enhanced mitochondrial membrane permeability changes and cytochrome $c$ release in the cells expressing high levels of Bcl-2.

Genistein modulates the distribution of Bcl-2 and Bax in the mitochondrial fractions of MCF-7/PV and MCF-7/Bcl-2 cells. 


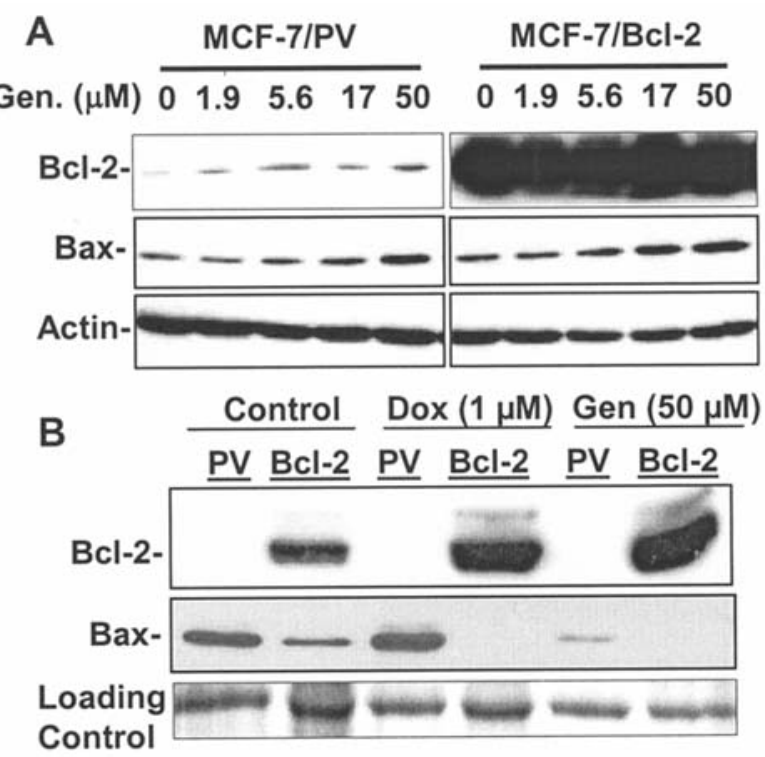

Figure 6. Bcl-2 and Bax levels in genistein treated $\mathrm{MCF}-7 / \mathrm{pv}(\mathrm{PV})$ and MCF-7/Bcl-2 (Bcl-2) cells. A, Bcl-2 and Bax levels in whole cell lysate. $\mathrm{MCF}-7 / \mathrm{PV}$ cells and $\mathrm{MCF}-7 / \mathrm{Bcl}-2$ cells were treated with genistein at indicated concentrations for $48 \mathrm{~h}$. Protein levels of Bax and Bcl-2 in the whole cell lysate were detected using Western blotting. B, Bcl-2 and Bax levels in the mitochondrial fraction. MCF-7/PV cells and MCF-7/Bcl-2 cells were treated with $0.1 \%$ DMSO (Control), $1 \mu \mathrm{M}$ of doxorubicin (Dox) or $50 \mu \mathrm{M}$ of genistein (Gen) for $48 \mathrm{~h}$. Mitochondrial fractions were prepared as described in Materials and methods. Bax and Bcl-2 protein levels were detected using Western blotting. After probing with $\mathrm{Bcl}-2$ and Bax, the membrane was stained with $0.1 \%$ amido black $10 \mathrm{~B}$. Signal of a $60-\mathrm{kDa}$ non-specific band was used as the loading control.

Interaction between $\mathrm{Bcl}-2$ and $\mathrm{Bax}$ is critical in the regulation of cytochrome $c$ release. Upregulation of Bax and downregulation of $\mathrm{Bcl}-2$, or increased $\mathrm{Bax} / \mathrm{Bcl}-2$ ratio, has been observed in many studies of genistein-induced apoptosis (3). We therefore examined Bcl-2 and Bax levels in the whole cell lysates of MCF-7/PV and MCF-7/Bcl-2 cells treated with genistein. In MCF-7/PV cells, genistein modestly induced the expression of endogenous $\mathrm{Bcl}-2$ at concentrations ranging from 1.9 to $50 \mu \mathrm{M}$ (Fig. 6A). Bcl-2 levels in genistein treated $\mathrm{MCF}-7 / \mathrm{Bcl}-2$ cells, however, were consistently high due to the expression of exogenous Bcl-2. Furthermore, genisteininduced Bax expression in both $\mathrm{MCF}-7 / \mathrm{PV}$ and $\mathrm{MCF}-/ \mathrm{Bcl}-2$ cells, whereas more in the latter. In contrast to the increased $\mathrm{Bax} / \mathrm{Bcl}-2$ ratio in genistein treated MCF-7/PV cells, the ratio in $\mathrm{MCF}-7 / \mathrm{Bcl}-2$ cells was consistently lower. These results suggest that increased $\mathrm{Bax} / \mathrm{Bcl}-2$ ratio in control cells might be a proapoptotic factor in the control cells, but not in $\mathrm{MCF}-7 / \mathrm{Bcl}-2$ cells. It suggests that if $\mathrm{Bax} / \mathrm{Bcl}-2$ ratio exceeds a certain threshold, excessive $\mathrm{Bcl}-2$ may promote cytochrome $c$ release. In addition, since it was reported that Bcl-2 could be cleaved by caspases and turned into a Baxlike proapoptotic molecule (35), we particularly examined whether genistein induced $\mathrm{Bcl}-2$ cleavage in these cells. We found that Bcl-2 cleavage was not detected in either cell line treated with genistein (data not shown).

Since distribution/translocation of Bcl-2 family members is a factor affecting their function (36), we then analyzed Bcl-2 and Bax distribution in the mitochondrial fraction. Under the given conditions, Bcl-2 was only detected in
MCF-7/Bcl-2 cells (Fig. 6B). In contrast to no fluctuation in $\mathrm{Bcl}-2$ levels in the whole cell lysate of $\mathrm{MCF}-7 / \mathrm{Bcl}-2$ cells, a notable difference is that $\mathrm{Bcl}-2$ levels in the mitochondrial fractions of genistein treated $\mathrm{MCF}-7 / \mathrm{Bcl}-2$ cells increased significantly as compared to DMSO treated cells. Treatment with $1 \mu \mathrm{M}$ of doxorubicin also induced moderate increase of $\mathrm{Bcl}-2$ in the mitochondrial fractions. Increased Bcl-2 levels in mitochondrial fraction, but not in the whole cell lyste of MCF-7/Bcl-2 cells, suggest that genistein may induce Bcl-2 translocation to the mitochondria of these cells. Interestingly, Bax levels in mitochondrial fraction were inversely correlated with Bcl-2 levels. In DMSO treated control cells, Bax levels were lower in $\mathrm{MCF}-7 / \mathrm{Bcl}-2$ cells as compared to $\mathrm{MCF}-7 / \mathrm{PV}$ cells. Doxorubicin increased Bax levels in MCF-7/PV mitochondria but not in MCF-7/Bcl-2 cells. In response to genistein treatment, Bax levels were decreased in MCF-7/PV cells but not detectable in $\mathrm{MCF}-7 / \mathrm{Bcl}-2$ cells. These results suggest that genistein induced excessive accumulation of Bcl-2 in the mitochondria of $\mathrm{MCF}-7 / \mathrm{Bcl}-2$ cells, possibly due to translocation, and affected the anchorage of Bax protein in mitochondria. Disturbed Bcl-2/Bax distribution in mitochondria may lead to increased cytochrome $c$ release and consequent enhanced-apoptosis in these cells.

Genistein induces G2/M arrest in Bcl-2 overexpressing MCF-7 cells. Cell cycle arrest is another phenotype commonly associated with genistein-induced growth inhibition. To test whether Bcl-2 overexpression modulates genistein-induced cell cycle arrest, we treated MCF-7/PV and MCF-7/Bcl-2 cells with $50 \mu \mathrm{M}$ of genistein for 24 and $48 \mathrm{~h}$ (Fig. 7). We found that 48 -h treatment induced greater modification of cell cycle progression, although the patterns of cell cycle distribution of the same cell line at different time points were similar. As shown in Fig. 7, genistein induced cell growth arrest in both MCF-7/PV and MCF-7/Bcl-2 cell lines. However, in contrast to MCF-7/PV cells, which were mainly arrested in G0/G1 phases (Fig. 7B and F), genistein induced a significant increase of $\mathrm{G} 2 / \mathrm{M}$ arrest in $\mathrm{MCF}-7 / \mathrm{Bcl}-2$ cells (Fig. 7D and H). The results clearly indicate that genistein/ Bcl-2 interactions resulted in modified cell cycle arrest patterns, suggesting that alteration in cell cycle regulation may also contribute to the enhanced growth inhibition in genistein treated $\mathrm{MCF}-7 / \mathrm{Bcl}-2$ cells.

Effects of genistein on cell cycle regulators in control and Bcl-2 overexpressing MCF-7 cells. With distinctive changes in growth inhibition and cell cycle arrest in MCF-7/Bcl-2 cells, as compared to the control cells, we examined the expression of several key cell cycle regulators, including p53, p21, p27, cdc-2 and cyclin B1. In general, genistein upregulated p53 and p21, and downregulated cdc-2 and cyclin B1 in both cell lines (Fig. 8), which is consistent with previous reports (7,37-39). p27 expression was not significantly affected by genistein. Comparison between the two cell lines reveals some differential effects. It appears that overall p53 levels in MCF-7/Bcl-2 cells were lower than MCF-7/PV cells. Nevertheless, upregulation of p21 in $\mathrm{MCF}-7 / \mathrm{Bcl}-2$ cells was more evident than in the control cells, suggesting more factors might be involved in genistein-mediated upregulation of p21. In addition, cyclin B1 levels were also lower in MCF-7/ 
MCF-7/PV

MCF-7/Bcl-2

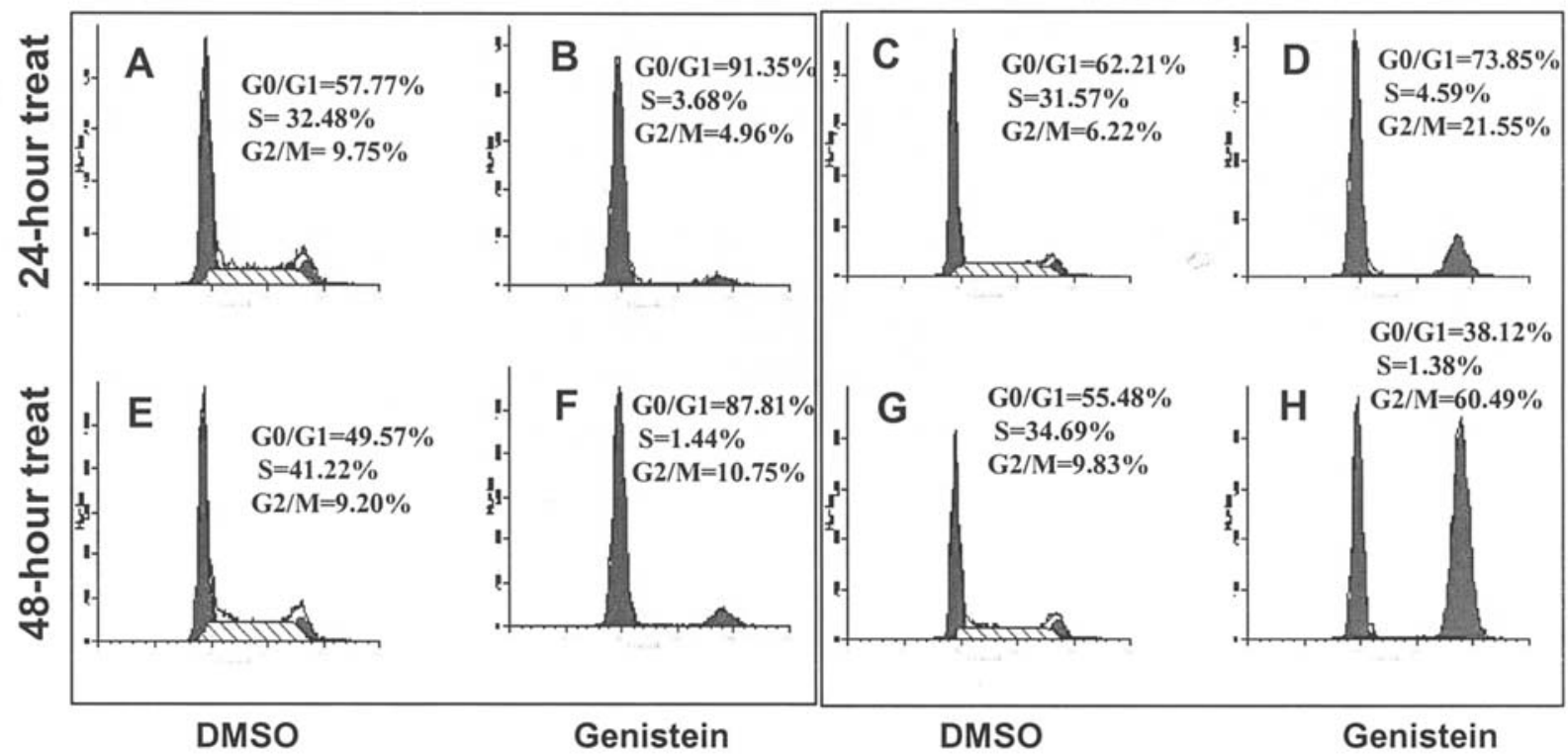

Figure 7. Overexpression of Bcl-2 modifies cell cycle arrest pattern in genistein treated cells. MCF-7/PV and MCF-7/Bcl-2 cells were treated with 0.1\% DMSO or $50 \mu \mathrm{M}$ of genistein for 24 or $48 \mathrm{~h}$. Treated cells were then fixed with $80 \%$ ethanol, followed by RNase A treatment and propidium iodine staining. DNA contents were measured using a FACSCalibur. Cell cycle distribution was analyzed using MultiFit software. Representative data of three independent experiments are presented.

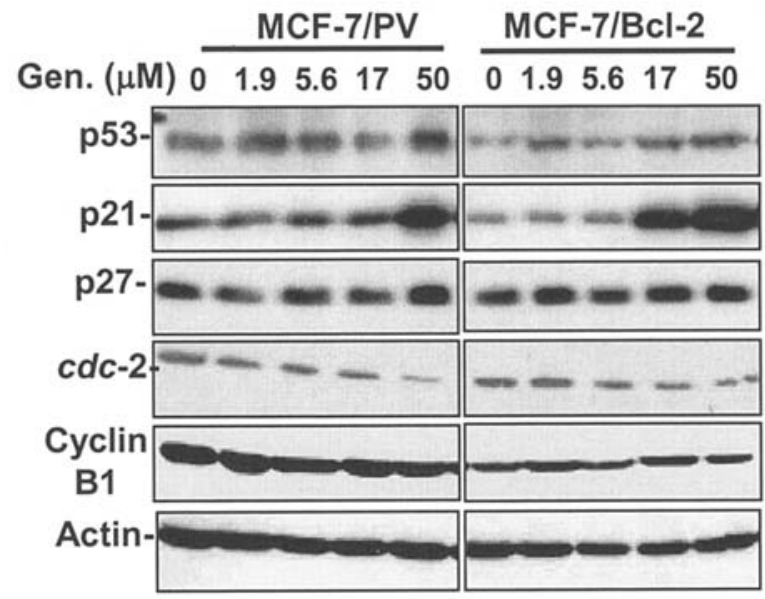

Figure 8. Effects of genistein on the expression of key cell cycle regulators in MCF-7/PV and MCF-7/Bcl-2 cells. Each cell line was treated with genistein at indicated concentrations for 48 h. Protein levels of p53, p21, p27, cdc-2, cyclin $\mathrm{B} 1$ and actin were detected using Western blotting.

Bcl-2 cells, as compared to control. Modified regulation of p21 and cyclin B1 by genistein in Bcl-2 overexpressing cells suggests that these factors may play a role in cell cycle arrest and sensitization resulted from Bcl-2-genistein interaction. Detailed mechanisms of genistein-mediated regulation of cell cycle progression in $\mathrm{MCF}-7 / \mathrm{Bcl}-2$ cells will be followed in future studies.

\section{Discussion}

Numerous studies have demonstrated that cellular responses to genistein vary significantly in a cell line-dependent manner. Other than ER status, however, the cellular factors that determine genistein responses are largely unknown. In this report, we focused on the effect of genistein on isogenic breast cancer cell lines with different Bcl-2 levels. We found that MCF-7 cells expressing high levels of Bcl-2 were more sensitive, rather than resistant, to genistein. This novel finding not only advances our understanding of genistein-mediated growth inhibition/apoptosis, but may also shed some light on the association between Bcl-2 overexpression and improved outcomes in breast cancers, a paradox observed in clinical studies.

Bcl-2 is a well known anti-apoptotic protein. It inhibits apoptosis and promotes cellular survival mainly by interfering with the translocation and subsequent oligomerization of $\mathrm{Bax} / \mathrm{Bak}$, which prevents the release of cytochrome $c$ and other apoptotic factors from the mitochondria (21). Overexpression of Bcl-2 has been associated with tumor development and chemoresistance in some tumors (26). Despite these facts, increasing reports suggest that Bcl-2 may switch its role from an anti-apoptotic protein to a proapoptotic molecule under certain circumstances. One aspect of the switch was mediated by caspase cleavage. Bcl-2 can be cleaved by activated caspase-3, resulting in Bax-like proapoptotic fragment, which enhances apoptotic execution in a feedback manner (35). It was also reported that Bcl-2 overexpression in testicular germline tumor cells induces enhanced cell death by downregulating Bcl-xL (40). In a mechanistic study, it was reported that $\mathrm{Bcl}-2$ is converted to a proapoptotic protein by interacting with nuclear receptor Nur77/TR3 (41). In addition, it was reported that transient high level expression of Bcl-2 induces cell death independent of Bax and Bak $(42,43)$. Given the possible conversion of Bcl-2 into a proapoptotic protein, identification of the factors/conditions that may induce such a conversion would have significant implication in clinical oncology. Supported by the results 
from both MTT and clonogenic assays, our data demonstrate that MCF-7 cells overexpressing high levels of Bcl-2 are more sensitive to genistein, suggesting that genistein is a factor that facilitates conversion of $\mathrm{Bcl}-2$ into a proapoptotic protein.

To study the mechanisms of the enhanced apoptosis/growth inhibition in genistein treated $\mathrm{MCF}-7 / \mathrm{Bcl}-2$ cells, we have examined a number of markers that are associated with either the effect of genistein or function of Bcl-2. Our results suggest a correlation between enhanced apoptosis and modified mitochondrial regulation in genistein treated $\mathrm{MCF}-7 / \mathrm{Bcl}-2$ cells. It has been known that cytochrome $c$, along with AIF and $\mathrm{Smac} / \mathrm{Diablo}$, is released from the inter-membrane space of mitochondria into the cytosol through the mitochondrial permeability transition pore (PTP) $(42,43)$. Loss of mitochondrial potential (membrane depolarization) induces PTP formation $(44,45)$. Therefore, increased mitochondrial depolarization and cytochrome $c$ release appear to be a major step leading to enhanced apoptosis in genistein treated MCF-7/Bcl-2 cells. However, since Bcl-2 is best known as an anti-apoptotic protein that prevents cytochrome $c$ release, the intriguing question is how genistein induces enhanced PTP formation and cytochrome $c$ release. Clearly, this cannot be explained by simple $\mathrm{Bax} / \mathrm{Bcl}-2$ ratio in those cells, because MCF-7/Bcl-2 cells express high levels of Bcl-2. On the contrary, our results suggest that when Bcl-2 levels reach a certain threshold and become dominant over Bax levels, more Bcl-2 may promote PTP formation. Given that Bcl-2 levels were increased in the mitochondrial fractions of the treated $\mathrm{MCF}-7 / \mathrm{Bcl}-2$ cells, it is possible that genistein induces Bcl-2 translocation and enriches Bcl-2 loading on mitochondrial membrane, which induced more PTP formation and cytochrome $c$ release. How genistein induces Bcl-2 translocation and how Bcl-2 induces PTP formation requires further study. In particular, how Bcl-2 levels are inversely correlated with Bax needs further investigation. Since MCF-7/ Bcl-2 cells are sensitive to the induction of mitochondrial depolarization and cytochrome $c$ release, our cell lines may be a useful model for these studies. In addition, although Bcl-2 could be converted into a proapoptotic protein by caspase-3 cleavage and interaction with Nur77, we have not detected any Bcl-2 cleavage or Nur77 upregulation in either cell lines treated with genistein (data not shown). Therefore, these factors are unlikely to be the major cause of enhanced growth inhibition in MCF-7/Bcl-2 cells. However, whether Nur77 translocation was associated with Bcl-2 translocation warrants further study.

Increased cell cycle arrest at $\mathrm{G} 2 / \mathrm{M}$ phases in genistein treated MCF-7/Bcl-2 cells suggests that modulation of cell cycle progression may also contribute to enhanced growth inhibition in these cells. Previous studies indicate that either genistein or Bcl-2 alone could modulate cell cycle progression. Genistein was reported to arrest $\mathrm{LNCaP}$ prostate cancer cells at G1 phase (46) but arrest MCF-7 and HCG-27 cells at $\mathrm{G} 2 / \mathrm{M}$ phases $(17,47)$. For Bcl-2 overexpression induced arrest, most reports indicate a G0/G1 arrest $(48,49)$. However, Bcl-2 may also induce $\mathrm{G} 2 / \mathrm{M}$ arrest by physically interacting with and inhibiting Cdk-2 (50). In our own experiments, we found that, after genistein treatment, the percentage of $\mathrm{MCF}-7 / \mathrm{Bcl}-2$ cells in $\mathrm{G} 2 / \mathrm{M}$ phase significantly increased
(Fig. 7D and $\mathrm{H}$ ). We also found that genistein induces differential responses of $\mathrm{p} 21$, Bax and cyclin B1 between the two cell lines. The specific role of each of the modified factors in genistein-Bcl-2 interaction induced $\mathrm{G} 2 / \mathrm{M}$ arrest in MCF-7/Bcl-2 cells will be addressed in future studies.

Our results may be linked to the clinical data regarding the role of $\mathrm{Bcl}-2$ overexpression in breast cancer. Although most in vitro studies demonstrate that $\mathrm{Bcl}-2$ is an antiapoptotic protein and $\mathrm{Bcl}-2$ overexpression is associated with chemoresistance with certain types of tumors, including leukemia, neuroblastoma, and small cell lung cancer. However, a review of multiple publications including more than 1000 breast cancer patients suggests that $\mathrm{Bcl}-2$ overexpression is generally associated with a favorable outcome (29). Breast cancers overexpressing Bcl-2 also predict a better response to hormonal therapy and some regimens of chemotherapy, as compared to Bcl-2 negative cells $(51,52)$. Current understanding of Bcl-2 regulation remains inadequate to explain this paradoxical issue. Our results are similar to clinical observations. It appears that $\mathrm{Bcl}-2$ overexpressing cancers would benefit not only from hormonal therapy, but also from soy/genistein treatment. Our cell line model may be a useful tool to study this clinically relevant problem. Since genistein shares both hormonal modulator properties with tamoxifen and DNA damaging function with chemotherapeutic agents, further study is required to ascertain which of these properties is more closely related to genistein-induced conversion of $\mathrm{Bcl}-2$ into a proapoptotic protein. The results from the mechanistic studies on genistein-Bcl-2 interaction may be helpful in the explanation of $\mathrm{Bcl}-2$ as a favorable biomarker in breast cancers.

\section{Acknowledgements}

We thank Dr John Reed for providing the pCR-Bcl-2 plasmid, and Mr. James Collins and Ms. Debbie Monachella for assistance in manuscript preparation. This work was supported in part by the residency training program of the Department of Pathology at University of Oklahoma Health Sciences Center.

\section{References}

1. Messina MJ, Persky V, Setchell KD and Barnes S: Soy intake and cancer risk: a review of the in vitro and in vivo data. Nutr Cancer 21: 113-131, 1994.

2. Lamartiniere CA: Protection against breast cancer with genistein: a component of soy. Am J Clin Nutr 71: S1705-S1709, 2000.

3. Sarkar FH and Li Y: Mechanisms of cancer chemoprevention by soy isoflavone genistein. Cancer Metastasis Rev 21: 265-280, 2002 .

4. Cotroneo MS, Wang J, Fritz WA, Eltoum IE and Lamartiniere CA: Genistein action in the prepubertal mammary gland in a chemoprevention model. Carcinogenesis 23: 1467-1474, 2002.

5. Yang X, Edgerton SM, Kosanke SD, et al: Hormonal and dietary modulation of mammary carcinogenesis in mouse mammary tumor virus-c-erbB-2 transgenic mice. Cancer Res 63: 2425-2433, 2003.

6. Margeat E, Bourdoncle A, Margueron R, Poujol N, Cavailles V and Royer C: Ligands differentially modulate the protein interactions of the human estrogen receptors alpha and beta. $\mathrm{J}$ Mol Biol 326: 77-92, 2003.

7. Shao ZM, Shen ZZ, Fontana JA and Barsky SH: Genistein's 'ER-dependent and independent' actions are mediated through ER pathways in ER-positive breast carcinoma cell lines. Anticancer Res 20: 2409-2416, 2000. 
8. Zand RS, Jenkins DJ and Diamandis EP: Steroid hormone activity of flavonoids and related compounds. Breast Cancer Res Treat 62: 35-49, 2000.

9. De Lemos ML: Effects of soy phytoestrogens genistein and daidzein on breast cancer growth. Ann Pharmacother 35: 1118-1121, 2001

10. Wang C and Kurzer MS: Effects of phytoestrogens on DNA synthesis in MCF-7 cells in the presence of estradiol or growth factors. Nutr Cancer 31: 90-100, 1998.

11. Akiyama T, Ishida J, Nakagawa S, et al: Genistein, a specific inhibitor of tyrosine-specific protein kinases. J Biol Chem 262: $5592-5595,1987$.

12. Akiyama T and Ogawara H: Use and specificity of genistein as inhibitor of protein-tyrosine kinases. Methods Enzymol 201: 362-370, 1991.

13. Theodorescu D, Laderoute KR, Calaoagan JM and Guilding KM: Inhibition of human bladder cancer cell motility by genistein is dependent on epidermal growth factor receptor but not p21ras gene expression. Int J Cancer 78: 775-782, 1998.

14. Markovits J, Linassier C, Fosse P, et al: Inhibitory effects of the tyrosine kinase inhibitor genistein on mammalian DNA topoisomerase II. Cancer Res 49: 5111-5117, 1989.

15. Davis JN, Kucuk O and Sarkar FH: Genistein inhibits NF-kappa B activation in prostate cancer cells. Nutr Cancer 35: 167-174, 1999.

16. Kang JL, Lee HW, Lee HS, et al: Genistein prevents nuclear factor-kappa B activation and acute lung injury induced by lipopolysaccharide. Am J Respir Crit Care Med 164: 2206-2212, 2001.

17. Matsukawa Y, Marui N, Sakai T, et al: Genistein arrests cell cycle progression at G2-M. Cancer Res 53: 1328-1331, 1993.

18. Li Y, Upadhyay S, Bhuiyan M and Sarkar FH: Induction of apoptosis in breast cancer cells MDA-MB-231 by genistein. Oncogene 18: 3166-3172, 1999.

19. Lian F, Bhuiyan M, Li YW, Wall N, Kraut M and Sarkar FH: Genistein-induced G2-M arrest, p2 $1^{\mathrm{WAF} 1}$ upregulation, and apoptosis in a non-small-cell lung cancer cell line. Nutr Cancer 31: 184-191, 1998.

20. Shao ZM, Alpaugh ML, Fontana JA and Barsky SH: Genistein inhibits proliferation similarly in estrogen receptor-positive and negative human breast carcinoma cell lines characterized by $\mathrm{P} 21^{\mathrm{WAF} 1 / \mathrm{CIP} 1}$ induction, G2/M arrest, and apoptosis. J Cell Biochem 69: 44-54, 1998.

21. Constantinou AI, Kamath N and Murley JS: Genistein inactivates bcl-2, delays the G2/M phase of the cell cycle, and induces apoptosis of human breast adenocarcinoma MCF-7 cells. Eur J Cancer 34: 1927-1934, 1998.

22. Harris MH and Thompson CB: The role of the Bcl-2 family in the regulation of outer mitochondrial membrane permeability. Cell Death Differ 7: 1182-1191, 2000.

23. Petros AM, Olejniczak ET and Fesik SW: Structural biology of the Bcl-2 family of proteins. Biochim Biophys Acta 1644: 83-94, 2004.

24. Cory $\mathrm{S}$ and Adams JM: Killing cancer cells by flipping the Bcl-2/ Bax switch. Cancer Cell 8: 5-6, 2005.

25. Kim R: Unknotting the roles of Bcl-2 and Bcl-xL in cell death. Biochem Biophys Res Commun 333: 336-343, 2005.

26. Kusenda J: Bcl-2 family proteins and leukemia. Minireview. Neoplasma 45: 117-122, 1998.

27. Cory S, Huang DC and Adams JM: The Bcl-2 family: roles in cell survival and oncogenesis. Oncogene 22: 8590-8607, 2003.

28. Sinicrope FA, Hart J, Michelassi F and Lee JJ: Prognostic value of bcl-2 oncoprotein expression in stage II colon carcinoma. Clin Cancer Res 1: 1103-1110, 1995.

29. Shibata Y, Hidaka S, Tagawa Y and Nagayasu T: Bcl-2 protein expression correlates with better prognosis in patients with advanced non-small cell lung cancer. Anticancer Res 24: 1925-1928, 2004.

30. Daidone MG, Luisi A, Veneroni S, Benini E and Silvestrini R: Clinical studies of Bcl-2 and treatment benefit in breast cancer patients. Endocr Relat Cancer 6: 61-68, 1999.

31. Elledge RM, Green S, Howes L, et al: bcl-2, p53, and response to tamoxifen in estrogen receptor-positive metastatic breast cancer: a Southwest Oncology Group study. J Clin Oncol 15: 1916-1922, 1997.

32. Yang XH, Sladek TL, Liu X, Butler BR, Froelich CJ and Thor AD: Reconstitution of caspase 3 sensitizes MCF-7 breast cancer cells to doxorubicin- and etoposide-induced apoptosis. Cancer Res 61: 348-354, 2001.
33. Bossy-Wetzel E and Green DR: Assays for cytochrome c release from mitochondria during apoptosis. Methods Enzymol 322: 235-242, 2000.

34. Wang C and Kurzer MS: Phytoestrogen concentration determines effects on DNA synthesis in human breast cancer cells. Nutr Cancer 28: 236-247, 1997.

35. Smiley ST, Reers M, Mottola-Hartshorn C, et al: Intracellular heterogeneity in mitochondrial membrane potentials revealed by a J-aggregate-forming lipophilic cation JC-1. Proc Natl Acad Sci USA 88: 3671-3675, 1991.

36. Cheng EH, Kirsch DG, Clem RJ, et al: Conversion of Bcl-2 to a Bax-like death effector by caspases. Science 278: 1966-1968, 1997.

37. Gross A, Jockel J, Wei MC and Korsmeyer SJ: Enforced dimerization of BAX results in its translocation, mitochondrial dysfunction and apoptosis. EMBO J 17: 3878-3885, 1998.

38. Ye R, Bodero A, Zhou BB, Khanna KK, Lavin MF and LeesMiller SP: The plant isoflavenoid genistein activates p53 and Chk2 in an ATM-dependent manner. J Biol Chem 276: 4828$4833,2001$.

39. Frey RS, Li J and Singletary KW: Effects of genistein on cell proliferation and cell cycle arrest in nonneoplastic human mammary epithelial cells: involvement of Cdc2, p21(waf/cip1), p27(kip1), and Cdc25C expression. Biochem Pharmacol 61: 979-989, 2001.

40. Choi YH, Zhang L, Lee WH and Park KY: Genistein-induced $\mathrm{G} 2 / \mathrm{M}$ arrest is associated with the inhibition of cyclin $\mathrm{B} 1$ and the induction of p21 in human breast carcinoma cells. Int $\mathrm{J}$ Oncol 13: 391-396, 1998.

41. Arriola EL, Rodriguez-Lopez AM, Hickman JA and Chresta CM: $\mathrm{Bcl}-2$ overexpression results in reciprocal downregulation of $\mathrm{Bcl}-\mathrm{X}(\mathrm{L})$ and sensitizes human testicular germ cell tumours to chemotherapy-induced apoptosis. Oncogene 18: 1457-1464, 1999.

42. Lin B, Kolluri SK, Lin F, et al: Conversion of Bcl-2 from protector to killer by interaction with nuclear orphan receptor Nur77/TR3. Cell 116: 527-540, 2004

43. Subramanian T and Chinnadurai G: Pro-apoptotic activity of transiently expressed BCL-2 occurs independent of BAX and BAK. J Cell Biochem 89: 1102-1114, 2003.

44. Uhlmann EJ, Subramanian T, Vater CA, Lutz R and Chinnadurai G: A potent cell death activity associated with transient high level expression of BCL-2. J Biol Chem 273: 17926-17932, 1998.

45. Bernardi P, Vassanelli S, Veronese P, Colonna R, Szabo I and Zoratti M: Modulation of the mitochondrial permeability transition pore. Effect of protons and divalent cations. J Biol Chem 267: 2934-2939, 1992

46. Petronilli V, Cola C, Massari S, Colonna R and Bernardi P: Physiological effectors modify voltage sensing by the cyclosporin A-sensitive permeability transition pore of mitochondria. J Biol Chem 268: 21939-21945, 1993.

47. Shen JC, Klein RD, Wei Q, et al: Low-dose genistein induces cyclin-dependent kinase inhibitors and G(1) cell-cycle arrest in human prostate cancer cells. Mol Carcinog 29: 92-102, 2000.

48. Pagliacci MC, Smacchia M, Migliorati G, Grignani F, Riccardi $\mathrm{C}$ and Nicoletti I: Growth-inhibitory effects of the natural phyto-oestrogen genistein in MCF-7 human breast cancer cells. Eur J Cancer 30A: 1675-1682, 1994.

49. O'Reilly LA, Huang DC and Strasser A: The cell death inhibitor Bcl-2 and its homologues influence control of cell cycle entry. EMBO J 15: 6979-6990, 1996.

50. Marvel J, Perkins GR, Lopez Rivas A and Collins MK: Growth factor starvation of bcl-2 overexpressing murine bone marrow cells induced refractoriness to IL-3 stimulation of proliferation. Oncogene 9: 1117-1122, 1994.

51. Crescenzi E, Sannino M, Tonziello G and Palumbo G: Association of Bcl-2 with cyclin a/Cdk-2 complex and its effects on Cdk-2 activity. Ann NY Acad Sci 973: 268-271, 2002.

52. Gasparini G, Barbareschi M, Doglioni C, et al: Expression of bcl-2 protein predicts efficacy of adjuvant treatments in operable node-positive breast cancer. Clin Cancer Res 1: 189-198, 1995.

53. Gee JM, Robertson JF, Ellis IO, et al: Immunocytochemical localization of BCL-2 protein in human breast cancers and its relationship to a series of prognostic markers and response to endocrine therapy. Int J Cancer 59: 619-628, 1994. 